\title{
A NON-LINEAR GOAL PROGRAMMING APPROACH TO MODELING INTRAREGIONAL ECONOMIC DEVELOPMENT
}

\author{
Ronald W. Spahr and Richard F. Deckro*
}

\section{Introduction}

State and local economic planners historically have been plagued by the sensitivity of regional economics to exogenously determined economic forces. Economic changes may be caused by fluctuations in regional exports, federal government expenditures, and/or externally financed investments, among other factors. A major task of regional economic analysts, therefore, is to develop policies and plans that will reduce the effects and costs of exogenous shocks. The purpose of this paper is to demonstrate the usefulness of a polynomial goal programming model in establishing a benchmark industrial structure which could be used to guide planning and policy efforts.

Regional economic planning and development may be characterized as an attempt to satisfy a set of potentially conflicting objectives. In an environment composed of uncertain demands for regional exports, varying capital investments, and divergent public and private interests, the economic planner is faced with multiple and potentially conflicting objectives. These objectives might include such factors as minimizing employment volatility and maximizing per capita income while controlling the region's economic growth rate. Typically, the economic planner must establish priorities if all the objectives cannot be completely and/or simultaneously satisfied. The widespread acceptance of prioritized objectives in other contemporary planning and management practices has stimulated the adoption of goal programming. Charnes and Cooper (1977), Dyer (1972), Harrold, Leotta, Wallace and Wendell (1978), Ignizio (1976, 1978, 1979), Kornbluth (1973), Lee (1972), Romero (1986), Rosenthal (1979), and Zanikas and Gupta (1985), among others, provide reviews of goal programming applications.

Goal programming is often used to satisfy a set of potentially conflicting goals or objectives by formulating each goal as a single constraint or a series of constraints. The objective function in the goal program minimizes the pertinent deviations from the goal target values. Thus, the nearer the optimal solution to meeting all of the goals of the problem, the smaller the optimal objective function value.

\footnotetext{
*Ronald Spahr is an associate professor of finance and Richard Deckro is an associate professor of industrial and operations management in the Department of Business Administration, College of Commerce and Industry at the University of Wyoming, Laramie, Wyo.
}

Conventional linear and quadratic goal programming models have been developed on the presumption of the existence of a preemptive priority structure which precludes the possibility of tradeoffs between goal levels. In such preemptive structures one goal must be satisfied completely before a second, third, or lower level goal will be considered. As Zeleny (1982) demonstrates, by using preemptive weights, conventional goal programming solutions can turn out to be dominated. "Polynomial Goal Programming" (Deckro and Hebert, forthcoming) attempts to address this difficulty.

While some decisions possess preemptive priority structures, regional economic planning and analysis encompasses goals that need not be achieved completely before consideration is given to lower priority goals or objectives. At some point it may be more desirable to satisfy a lower level goal rather than "wiring out" the last bit of "satisfaction" from an upper goal. This paper outlines a procedure for modeling and solving economic planning and analysis problems with "intergoal trade-offs" while retaining the deviational variable as a measure of satisfaction. By adapting the modeling procedure suggested by Deckro and Hebert, the objective function for the regional goal program is expressed as a polynomial, rather than the traditional additive weighting or preemptive weights process. Intergoal trade-offs can be achieved subject to the perceived marginal rates of substitution between goal deviations. The polynomial approach provides a technique to drive a regional economic planning solution in the direction of the target value for a particular goal, only if the largest overall increase in marginal utility derived from the reduction of deviations is gained from the planning objectives. The non-linearity of the economic environment is maintained. Such a model also can accommodate formulations requiring the traditional preemptive priority structure combined with trade-offs within the same levels.

The second section of this paper briefly reviews possible economic planning criteria that may reduce the effects of exogenous shocks. The third section presents a generalized regional polynomial goal programming model with some suggested objectives and constraints. Section four illustrates the approach with a hypothetical example. Section five discusses the mathematical programming solution procedure used to solve the example problem. The sixth section summarizes the conclusions of the study. 


\section{Economic and Planning Background}

This paper provides a one-period normative model that may be used as a guide or benchmark by which the economic planner may develop policies and plans for regional economic development. The model can accommodate a region that could be as large as a small country or as small as a city, provided sufficient relevant data are available. The model is capable of serving as a guide for development in a five- to 10 -year time horizon. The fourdigit Standard Industrial Classification code disaggregation level for industries is recommended. Although there are over 400 industries at this disaggregation level, normally only a small subset of these industries would be feasible for economic development in a given region. The actual selection would depend on regional preference, economic advantages, diversification considerations and political realities. While selections would vary from region to region, the informed judgement of the planning professional would be of a paramount importance to the decision. Thus, the model in most practical applications will be of manageable size.

At the four-digit level of disaggregation, not all of the industries will be homogeneous, and some may display spatial differences (Harding and Phillips, 1983); however, these problems are not likely to be serious if the size of the region is fairly large. As Kort (1981) found, the inverse relationship that exists between economic instability and industrial diversification varies with region size.

The work of Thompson (1965) suggests a number of possible objectives for such a regional model. These include such goals as maximizing per capital income, stabilizing the level of employment, and controlling the future growth rate of the economic region. Thompson distinguishes three kinds of instability: seasonal instability, cyclical instability, and growth instability. While the proposed model can address each of these sources of instability, our primary discussion will center on reducing a region's medium-term (five to 10 years) instability. According to Thompson, medium-term instabilities are usually associated with cycles in the national or international economy which may cause amplified fluctuations in regional exports and externally financed investments.

Thompson (1965), Clark (1934), and Vining (1945, 1946) all suggest that there is a close causal relationship between the local industry mix and the cyclical instability of that area. The local business cycles of a region seem to reflect, in large part, the cyclical characteristics of its principal industries and major exports. Increases and decreases in production or employment in a set of regional industries over the midterm-five to 10 years-are not likely to be independent or randomly distributed. They tend, rather, to be linked with common industry-wide increases and decreases. Industrial diversification would seem then, according to Thompson, to be a process of averaging the responses of regional industries to different industry-wide cycles. Planned diversification, rather than uncontrolled diversification, should result in regional economic cycles that are less severe than if planning had not taken place. Along this line, Conroy (1972) proposes that individual industries need to be weighted by an index of their relative industry-wide tendencies to fluctuate. (While industry-wide data have been used here, specific regional data could be used in the modeling technique where such data are available.)

With respect to growth instability, Thompson suggests that the policy prescription is simple: One needs to generate a local industry mix of complementary growth trends-a mix of young, mature, and aging industries. If such a mix is associated with a region, that region could be expected to have stable growth trends over the long run.

In his study conceming industrial diversification and regional stability, Conroy (1972) draws concepts and techniques from financial portfolio theory and suggests that industrial diversification is an analogous problem. Just as stockbrokers attempt to reduce the risks, Conroy suggests that regional planners should view industrial diversification as the pooling of risk of fluctuations in output and employment. He proposes that weights used in summing the contribution of individual industries to total regional fluctuations should be measures of historical instability (such as the variance). Conroy further suggests that a potentially appropriate indirect measure of the effect of industrial linkages upon fluctuations would be the covariances between industries as measured at the industry-wide level. When the proportions of employment in each industry in an area are multiplied by the variances and covariances, the product can be summed to yield a single aggregate measure of expected fluctuations for each region. This value is the industrial portfolio variance, which should be as low as possible.

The level of per capita income in a region also has been suggested as a planning objective. Borts and Stein (1964) suggest that wage level will be determined by the ratio of capital to labor. The greater the amount of capital per laborer in a region, the higher the wage level.

Certain industries, which might be desirable in a region due to higher per capita income and/or stabilizing effects on the labor force, may require subsidies. Conroy (1975) advocates such subsidies. He suggests that the same stabilizing industries would be required by all regions in the national economy; however, in another study, Conroy (1974) found this not to be the case. The principal reason for this result was that the effect of expanding any 
single industry depends upon the whole prior industrial structure and the relationship of the variability of the expanding industries to all of the preexistent employment sources.

\section{Illustrative Model}

The model presented below utilizes a polynomial expression of the pertinent deviational variables from each goal target level as a method of modeling both intra- and intergoal preference trade-offs. The ability to vary the powers and coefficients of the deviational variables in the objective function replaces the need for strict preemption. As a particular deviational variable is forced near zero (i.e., as the goal approaches its target level), diminishing marginal returns result. ${ }^{1}$

The model presented is for a region that may be as large as an entire state, has existing employment, and considers attracting some new industries to increase employment, total wages, and salaries. While the existing employment may be in more than one four-digit SIC code industry, all of the existing industries are aggregated into a single sector. The decision maker can specify a target growth rate of the existing aggregate sector or this sector may be assumed constant. The total additional employment is exogenous and is derived from new industry attracted to the region. However, the distribution of new employment over the new industry candidates is endogenous or determined by the desires of the decision maker in specifying the future growth rate of employment and the growth rate in per capita income. The modeling approach will be illustrated with four sets of goal constraints. Other possible constraints or goals could be added, however, if the modeling environment dictated their inclusion.

\section{Constraint 1: Minimization of Employment Variance}

Industrial diversification will be considered as analogous to the financial portfolio problem. The regional planner should view industrial diversification as the pooling of the risk of fluctuations in employment and attempt to minimize industrial employment variance in the feasible set of industries where employment figures may be obtained from Bureau of Labor Statistics data. The first constraint attempted to force employment variance to $\mathrm{zero}^{2}$ as indicated below:

$$
\mathrm{w}_{\mathrm{E}}^{2} \sigma_{\mathrm{E}}^{2}+2 \mathrm{w}_{\mathrm{E}} \sum_{\mathrm{i}=1}^{N} \mathrm{~W}_{\mathrm{i}} \sigma_{\mathrm{E}}+\sum_{\mathrm{j}=1}^{\mathrm{N}} \sum_{\mathrm{i}=1}^{N} \mathrm{w}_{\mathrm{i}} \mathrm{W}_{\mathrm{j}} \sigma_{\mathrm{i}}-\mathrm{d}_{1}=0,
$$

where

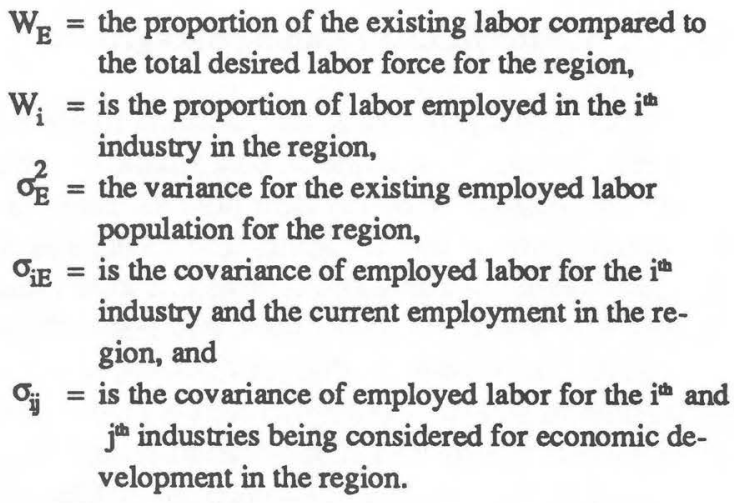

Constraint 1 attempts to minimize the variance of employment in the region by selecting the appropriate weight, $W_{i} s$. A scaling problems exists, however, in the constraint. Since most industries would employ considerably more labor than that within a single region, the variance and covariance terms for each $i^{\text {th }}$ industry would be of larger magnitude than the variance term for the region. To overcome this scaling problem, the total number of employees in an industry is scaled so that the industry has the same number of employees as the region of interest. This is accomplished by multiplying the mean, variance, and covariance data from the industry by the ratio of the labor force in the region to the total labor force in the industry or the ratio squared, whichever is mathematically appropriate. When the proportions of employment in each feasible industry in a region, $i$, are multiplied by the variances and covariances, as in Constraint 1 , the product, $W_{i}$, can be summed to yield the industrial portfolio variance.

\section{Constraint 2: Labor Force Income and Growth}

The wage and salary levels in a region are determined by the ratio of capital to labor and by the efficiency of the use of this capital. Using this concept, Constraint 2 attempts to force wages and salaries to a desired target level while simultaneously controlling the growth rate of the labor force at a desired rate. Thus,

$$
\begin{aligned}
& \mathrm{W}_{\mathrm{E}} \mathrm{K}^{\alpha} \mathrm{L}_{\mathrm{E}}(1+\mathrm{g})+\sum_{\mathrm{i}=1}^{N} \mathrm{~W}_{\mathrm{I}} \mathrm{K}^{\alpha^{\alpha}} \mathrm{L}_{\mathrm{E}}(1+\mathrm{g})+\mathrm{d}_{1}-\mathrm{d}_{3}= \\
& K_{E}^{o_{8}} L_{E}(1+g)(1+r)
\end{aligned}
$$

where

$$
\begin{aligned}
& K^{\alpha_{B}}=\text { the efficiency of capital usage in the existing labor } \\
& \text { force, } \\
& L_{E}=\text { the existing labor force, } \\
& K^{\alpha_{1}}=\text { the efficiency of capital usage for the } i^{\text {th }} \text { proposed }
\end{aligned}
$$


industry,
$\mathrm{g}=$ the growth rate in the labor force desired,
$\mathbf{r}=$ the growth rate in the level of per capita income, and

the other variables as previously defined.

The levels $g$ and $r$ are determined by the region's planners. The value $g$ is the desired growth rate for labor and would include currently unemployed labor as well as the desired growth in the labor force over the planning horizon. The value $r$ is the growth rate in per capita income.

A modified Cobb-Douglas production function of the form $Y=K^{\circ} L_{T}$ may be used to represent the total income received by labor. $K$ is the capital allocated per unit of labor, $\alpha$ is the efficiency coefficient, and $L_{T}$ may be termed the stock of effective labor after economic development has occurred. As an example, a position with an annual wage of $\$ 30,000$ and $\$ 100,000$ of capital invested per employee would have an efficiency coefficient of $\alpha=$ $0.89542 .^{3}$

Constraint 2 attempts to control for both the size of the labor force and the per capita income of the labor force. By increasing $(1+r)$, the growth rate of per capita income, more importance will be placed on the capital per unit of labor and the efficiency of that capital in generating higher per capita income. The factor $(1+g)$, the growth rate of the labor force, controls the desired size of the labor force after economic development, while $(1+r)$ controls the labor per capita income.

\section{Constraint 3: Growth of the Labor Force}

The third constraint attempts to control for the size of the labor force. The size of the labor force, subsequent to economic development, is projected to be $\mathrm{L}_{\mathrm{B}}(1+\mathrm{g})$. Constraint 3 will, however, allow the actual size to vary from this level:

$$
W_{E}\left(L_{E}(1+g)\right)-d_{4}+d_{5}=L_{E}
$$

This constraint allows $W_{E}$ (the proportion of the existing labor to the total desired labor force after development) to be a decision variable.

Coupled with Constraint 3 , a fourth constraint forces the proportion of labor employed in the $i^{\text {ih }}$ industry plus the proportion of the existing labor force to sum to one. This condition assumes that all of the existing labor force, plus the new labor force resulting from expansion, will be fully employed as shown in the equation:

$$
\sum_{i=1}^{N} w_{i}+w_{E}=1 .
$$

Finally, the standard non-negativity conditions and upper bounds are included in Constraint 5 below:

$$
0 \leq W_{E}, W_{1} \text { to } W_{N} \leq 1 .
$$

Note that all weights or proportions of the labor force in industry $i$ are constrained to the range from zero to one.

Equations 1,2,3,4, and 5 form the constraint set of the illustrative model. It is possible to include other goal constraints that may be desired by an economic planner. For example, it may be desirable to add contraints on the region's ability or desire to attract any particular industry from the set of candidate industries. The model, as formulated, constrains total employment after new industries have entered. Nothing in the model, however, would prevent all increases in employment from coming from one single new industry. A constraint in a region-specific model could place an upper limit on the amount of industry which a region can attract or on the amount it wants to attract. Subscripts may be used to provide for the growth of the area according to specific employee skill levels. This might be done by expressing $W_{i}$ as $W_{i j}$, where $j$ represents a specific skill class or level. Target levels for each skill class $j$ would then be set and additional goal constraints developed.

\section{Objective Function}

In general, one optimizes a goal programming model by attempting to minimize selected deviational variables. As the appropriate deviational variables are driven closer to zero, the corresponding goal is brought closer to satiation. In polynomial goal programming, rather than use the more traditional pre-emptive weights, polynomial powers have been used to reflect the decision maker's preference. The objective is stated in general form as:

$$
\operatorname{Min} Z=\sum_{k=1}^{M} G_{k} d_{k}^{P}
$$

where

$$
\begin{aligned}
& \mathbf{k}=\text { the } \mathbf{k}^{\text {th }} \text { goal constraint in the set of } M \text { constraints, } \\
& \mathrm{d}_{\mathrm{z}}=\text { the deviation from the target level of constraint } \\
& k \text {, } \\
& G_{k}=\text { an algebraic numeric weight for the deviation } \\
& d_{\mathrm{k}^{\prime}} \text {, and } \\
& P_{k}=\text { a non-negative power associated with devia- } \\
& \text { tion } d_{k} \text {. }
\end{aligned}
$$

The magnitude of $P_{k}$ reflects the importance of satisfying the goal associated with $d_{k}$. As $P_{k}$ becomes larger, the underlying mathematics will make it more desirable to force $d_{k}$ to zero, thus satisfying the goal. At some point, however, $d_{k}$ will become small enough to allow some other goal to be pursued. 


\section{Example Problem}

The above model will be demonstrated using a hypothetical region which is almost exclusively dependent upon the energy industry for employment. Because of recent declines in employment in the energy industry and in light of its historical boom and bust cycles, the objective of the region's economic planners has become to attract new industries that will stabilize employment variations, individual income, and employment growth. As a result of the region's almost exclusive dependence on the energy industry, the existing employed labor force of 100,000 may be considered relatively homogencous.

It is assumed that economic devclopment and stabilization may be attained from five carefully chosen industries which could expand into the region. These industries are identified as electronics, plastics, banking, food processing, and tourism and recreation. The variance/covariance matrix for employment levels in this hypothetical setting is given in Table 1. The data are scaled to the size of the region's total labor force, as previously discussed. It is assumed in this example that the current average income per employee is $\$ 20,000$ and that the average capital per employee is $\$ 80,000$. Thus, the functions $\mathrm{Y}=\mathrm{K}^{\alpha} \mathrm{L}$ may be defined as $\mathrm{K}=\$ 80,000, \alpha=0.8772$ (as developed in note $3)$, and the current employed labor force equal to 100,000 . The resulting total income for the region is currently $\mathrm{Y}=$ $(80,000)^{0.872} 100,000=\$ 2,000,000,000$. The values for $K$ and $\alpha$ for the five industries being considered for industrial development in the region are given in Table $2 .{ }^{4}$

The weights and coefficients of the objective function deviations are determined from the subjective assess-

Table 1

Variance-Covariance Matrix for Employment in the Region and Five Potential Industries

\begin{tabular}{lcccccc}
\hline \hline & $\begin{array}{c}\text { Current } \\
\text { Labor Force }\end{array}$ & Electronics & Plastics & $\begin{array}{c}\text { Industry } \\
\text { Banking }\end{array}$ & $\begin{array}{c}\text { Food } \\
\text { Processing }\end{array}$ & $\begin{array}{c}\text { Tourism and } \\
\text { Recreation }\end{array}$ \\
\hline Current Labor Force & $1.0 \times 10^{8}$ & $3.3 \times 10^{7}$ & $3.6 \times 10^{7}$ & $4.0 \times 10^{7}$ & $3.0 \times 10^{7}$ & $2.18 \times 10^{7}$ \\
Electronics & & $1.12 \times 10^{8}$ & $1.98 \times 10^{7}$ & $3.52 \times 10^{7}$ & $3.3 \times 10^{7}$ & $2.64 \times 10^{7}$ \\
Plastics & & $8.2 \times 10^{7}$ & $7.2 \times 10^{6}$ & $2.25 \times 10^{7}$ & $1.89 \times 10^{7}$ \\
Banking & & & $6.4 \times 10^{7}$ & $8.0 \times 10^{6}$ & $1.6 \times 10^{7}$ \\
Food Processing & & & & $2.5 \times 10^{7}$ & $1.35 \times 10^{7}$ \\
Tourism and Recreation & & & & & & \\
\hline \hline
\end{tabular}

Table 2

Efficiency of Capital Usage for Each Proposed Industry

\begin{tabular}{lrcc}
\hline \hline Industry & \multicolumn{1}{c}{$\mathrm{K}$} & \multicolumn{1}{c}{$\alpha$} & Average per employee income \\
\hline Existing & $\$ 80,000$ & 0.8772 & $\$ 20,000$ \\
Electronics & 70,000 & 0.9077 & 25,000 \\
Plastics & 100,000 & 0.8704 & 22,500 \\
Banking & 150,000 & 0.8462 & 24,000 \\
Food Processing & 90,000 & 0.8682 & 20,000 \\
Tourism and Recreation & 80,000 & 0.8727 & 19,000 \\
\hline \hline
\end{tabular}


ments of the importance of the deviations from each of the constraints. Keeney and Raiffa (1976), MacCrimmon and Siu (1974) and MacCrimmon and Toda (1969) present several procedures which may be used to supplement the subjective evaluations. Khorramshahgol and Gousty (1986) have suggested using the Delphi approach in selecting goals and priorities in goal programming. The terms have been scaled to create deviations which are comparable and of the same dimension as their constraints. For example, Constraint 7 is the variance of the labor force and would have a dimension of employees squared, whereas, Constraint 8 controls the region's total income and would have a dimension in dollars. The resulting formulation for the example problem is shown in Table 3.

The coefficient for $d_{1}$ in the objective function is derived by first taking $d$, to the one-half power to compensate for the variance of regional employment in Constraint 1. A hypothetical coefficient of 0.57526 results in a deviation of 10,000 employees, $\left(d_{1}\right)^{0.5}$, having a value to
40,000 in the objective function. Thus, the function

$$
\left(d_{1}^{0.5}\right)^{1.1505}=d_{1}^{0.57526}
$$

will be zero if $d$ is zero, but will increase to 2,828 when $\left(d_{1}\right)^{0.5}$ is 1,000 and will increase to 40,000 when $\left(d_{1}\right)^{0.5}$ is 10,000 . Thus, an employment deviation of $10,000 \mathrm{em}$ ployees will reflect a value of 40,000 in the objective function, which will place higher priority on satisfying this goal.

The coefficients and weights for $d_{2}$ and $d_{3}$ are derived by assuming that each employee has an average income of $\$ 20,000$. Multiplying $d_{2}$ and $d_{3}$ by a weight of 0.00005 will convert the actual deviation in dollars to approximately a deviation in employee dimension. For Constraint 8 it was assumed that a deviation of 10,000 employees actually had an importance of three times the deviation of 10,000 employees (i.e., 30,000) if income for the region was below the desired level. Thus, $\left(d_{2}\right)^{1.11928}$ was the derived coeffi-

Table 3

Example Problem Formulation

polynomial objective:

$$
\operatorname{Min} Z=d_{1}^{0.575251}+0.00005 d_{2}^{1.11928}-0.00005 d_{3}+d_{4}^{1.07526}+d_{5}^{1.07526}
$$

\section{SUBJECT TO}

variance of labor force:

$$
\begin{aligned}
& 1.00 \times 10^{8} \mathrm{~W}_{\mathrm{E}}^{2}+1.12 \times 10^{8} \mathrm{~W}_{1}^{2}+8.10 \times 10^{7} \mathrm{~W}_{2}^{2}+6.40 \times 10^{7} \mathrm{~W}_{3}^{2}+2.5 \times 10^{7} \mathrm{~W}_{4}^{2}+9.00 \times 10^{6} \mathrm{~W}_{5}^{2}+ \\
& 2 \mathrm{~W}_{\mathrm{E}} \mathrm{W}_{1}\left(3.30 \times 10^{7}\right)+2 \mathrm{~W}_{\mathrm{E}} \mathrm{W}_{2}\left(3.60 \times 10^{7}\right)+2 \mathrm{~W}_{\mathrm{E}} \mathrm{W}_{3}\left(4.00 \times 10^{7}\right)+2 \mathrm{~W}_{\mathrm{E}} \mathrm{W}_{4}\left(3.00 \times 10^{7}\right)+ \\
& 2 \mathrm{~W}_{\mathrm{E}} \mathrm{W}_{5}\left(2.18 \times 10^{7}\right)+2 \mathrm{~W}_{1} \mathrm{~W}_{2}\left(1.98 \times 10^{7}\right)+2 \mathrm{~W}_{1} \mathrm{~W}_{3}\left(3.52 \times 10^{7}\right)+2 \mathrm{~W}_{1} \mathrm{~W}_{4}\left(3.30 \times 10^{7}\right)+ \\
& 2 \mathrm{~W}_{1} \mathrm{~W}_{5}\left(2.64 \times 10^{7}\right)+2 \mathrm{~W}_{2} \mathrm{~W}_{3}\left(7.20 \times 10^{6}\right)+2 \mathrm{~W}_{2} \mathrm{~W}_{4}\left(2.25 \times 10^{7}\right)+2 \mathrm{~W}_{2} \mathrm{~W}_{5}\left(1.89 \times 10^{7}\right)+ \\
& 2 \mathrm{~W}_{3} \mathrm{~W}_{4}\left(8.00 \times 10^{6}\right)+2 \mathrm{~W}_{3} \mathrm{~W}_{5}\left(1.60 \times 10^{7}\right)+2 \mathrm{~W}_{4} \mathrm{~W}_{5}\left(1.35 \times 10^{7}\right)-\mathrm{d}_{1}=0
\end{aligned}
$$

regional total income: $\quad(80,000)^{087 m}(100,000)(1+0.30) \mathrm{W}_{\mathrm{E}}+(70,000)^{0.907}(100,000)(1+0.30) \mathrm{W}_{1}+(100,000)^{0.8704}(100,000)(1+0.30) \mathrm{W}_{2}+$ $(150,000)^{0.8462}(100,000)(1+0.30) \mathrm{W}_{3}+(90,000)^{0.8682}(100,000)(1+0.30) \mathrm{W}_{4}+(80,000)^{0.8727}(100,000)(1+0.30) \mathrm{W}_{5}+$

$$
d_{2}-d_{3}=(80,000)^{0.872}(100,000)(1+0.30)(1+0.20)
$$

labor force growth:

$$
\begin{gathered}
W_{E}(100,000(1+0,30))-d_{4}+d_{5}=100,000 \\
W_{1}+W_{2}+W_{3}+W_{4}+W_{5}+W_{E}=1 \\
d_{1} \geq 0 ; i=1,2, \ldots, 5 \\
0 \leq W_{j} \leq 1 ; j=1,2, \ldots, 5 \\
0.7692 \leq W_{E} \leq 1 .
\end{gathered}
$$


cient. A higher than desired regional income, $d_{3}$, was considered desirable. Thus, the negative coefficient is placed on the deviation in the objective function.

The coefficient for $d_{4}$ and $d_{5}$ was obtained by assuming that a deviation above or below the projected employment growth rate had an importance of two times the actual deviation, assuming a deviation of 10,000 employees was found. This results in both $d_{4}$ and $d_{5}$ having a coefficient of 1.07526.

Constraint 7 uses the data in Table 1 to formulate the regional employment variance constraint. Constraint 8 uses the data in Table 2 to formulate the regional income constraint. It was assumed in the example that a 30 percent growth in employment and a 20 percent growth in average employee income were desirable. The right-hand side of Constraint 8 requires a total income for the region to be $\$ 3.12$ billion.

Constraint 9 controls the proportion of the existing industry after the economic development to be approximately equal to the ratio of current employment to employment after desired economic development. This constraint assumes that a region is not going to tear down the existing industry and start over. Thus, the weight of $W_{E}$ should be $(100,000 / 130,000)$, or approximately 0.76923 .

\section{Mathematical Programming Solutions}

The polynomial goal programming model is particularly amenable to solution by any of a number of gradient projection-based techniques, although some sensitivity to round-off may be exhibited. The example problem was solved using the generalized reduced gradient technique, GRG2, developed by Lasdon and Waren (1977) on the CYBER 760 at the University of Wyoming.

The results of the polynomial goal programming model are shown in Table 4. To achieve the goals dictated in the model, the regional planner should attempt to attract a company in the electronics industry that will employ about 19,218 people, a company in the plastics industry that will employ about 1,100 people, and a company in the banking industry that will employ about 9,340 people. The planner should also expand the tourism and recreation industry to employ 304 additional people and retain the existing industries that employ 100,000 people. It should be noted that the food processing industry was not chosen as a candidate for industrial development. This development was a result of the food processing industry's lower employee income, which, in turn, made it difficult to attain the desired income goal. In addition, food processing did

Table 4

Illustrative Example Solution

\begin{tabular}{ccl}
\hline \hline Solution & \multicolumn{1}{c}{ Value } & Proportions of Labor Force in Industry \\
\hline Objective Function & $2.816 \times 10^{5}$ & \\
$\mathrm{~W}_{1}$ & 0.14783 & Electronics \\
$\mathrm{W}_{2}$ & 0.00846 & Plastics \\
$\mathrm{W}_{3}$ & 0.07185 & Banking \\
$\mathrm{W}_{4}$ & 0.0 & Food Processing \\
$\mathrm{W}_{5}$ & 0.00234 & Tourism and Recreation \\
$\mathrm{W}_{\mathrm{B}}$ & 0.76923 & Existing Labor \\
$\mathrm{d}_{1}$ & 75.278 & \\
$\mathrm{~d}_{2}$ & 384.01 & \\
$\mathrm{~d}_{3}$ & 0.00039 & \\
$\mathrm{~d}_{4}$ & 0.0 & \\
$\mathrm{~d}_{3}$ & 0.0 & \\
\hline \hline
\end{tabular}


not provide the employment diversification found in the tourism and recreation industry.

\section{Conclusions}

The polynomial goal programming model suggested above is meant to provide the economic planner with a benchmark by which he or she may develop policies and plans for regional economic development. By utilizing the model to develop a benchmark structure where greater overall utility may be gained by attempting to satisfy a lower order goal rather than exhausting a higher level goal deviation, the preemptive feature of goal programming may be eliminated. The amount of acceptable deviation from an upper level goal is directly controlled by the rate of substitution between deviations at different goal levels. In the model, these rates of substitution are expressed in the objective function by varying the coefficients or weights $(G)$ and powers $(P)$ of the appropriate deviational variables. The premise of the model is that the economic planner finds it more manageable to express a desire or utility for varying levels of goal deviation than for a complex utility function. The goals of the above regional economic planning model are to minimize the variance of employment in the region while planning for employment growth and a desired average employee income.

This model is proposed as a normative one-period model that will guide the economic planner in future development of his or her region. Multiple periods can be considered, but at the cost of increased complexity. The model will identify the appropriate industries and the approximate size of those industries that will best match the expressed goals of the regional planner.

\section{Notes}

'For a further example of the use of polynomial goal programming, see Deckro and Hebert (forthcoming).

'The variances and covariances for a region's existing employment level and proposed industries' employment can be obtained by using historical employment data. Labor statistics, such as all employees, production workers, production worker average weekly earnings, production worker average hourly eamings, and production worker average weekly hours, are given weekly by SIC code industries in Supplement to Employment and Earnings, U.S. Department of Labor, Bureau of Labor Statistics. For industry trends and projections see U.S. Industrial Outlook, Prospects for Over 300 Industries, U.S. Department of Commerce, Bureau of Industrial Economics.

'In the function $Y=K^{\alpha} L_{r}, K$ is the capital-labor ratio and $K^{\alpha}$ is a wage rate. If we assume that there is a production function, $Q=F(C, L)$, where $C=$ capital, $L=$ labor and $Q=$ total production and the marginal product of labor is equal to the wage rate, then the shape of the production function can be determined by integration:

$$
\mathrm{MP}_{\mathrm{L}}=\frac{\partial \mathrm{Q}}{\partial \mathrm{L}}=\mathrm{K}^{\alpha}=\left(\frac{\mathrm{C}}{\mathrm{L}}\right)^{\alpha} .
$$

Thus,

$$
Q=\int\left(\frac{C}{L}\right)^{\alpha} d L+M,
$$

where

$$
\mathbf{M}=\mathbf{a} \text { constant of integration. }
$$

However, it is reasonable to assume that $\mathrm{Q}=0$ if $\mathrm{C}=\mathrm{L}=0$; thus, $M$ should equal zero. Then,

$$
Q=\int\left(\frac{C}{L}\right)^{\alpha} d L=\frac{C^{\alpha^{1-\alpha}}}{1-\alpha}
$$

which is the form of the familiar Cobb-Douglas production function,

where

$$
Q=A C^{\alpha} L^{1-\alpha} \text {. }
$$

$$
A=\frac{1}{1-\alpha}
$$

The purpose of this example is to clarify the use of the proposed model and has no empirical justification.

\section{References}

Borts, George H., and Jerome L. Stein. Economic Growth in a Free Market. New York: Columbia University Press, 1964.

Carlton, Dennis E. "The Location and Employment Choices of New Firms: Endogenous Variables." The Review of Economics and Satistics. 65:3 (1983). 440-449.

Charnes, A., and W. W. Cooper. "Goal Programming and Multiple Objective Optimizations." European Journal of Operational Research. (1977). 39-54.

Clark, J. M. Strategic Factors in Business Cycles. New York: Harper and Row, 1934.

Conroy, Michael E. Optimal Regional Industrial Diversification: A Portfolio-Analytic Approach. Unpublished Paper, 1972.

"Alternate Strategies for Regional Industrial Diversification." Journal of Regional Science. 14:1 (1974). 31-46.

\section{. The Challenge of Urban Economic} Development. Lexington, Mass.: Lexington Books.

Deckro, Richard F., and John E. Hebert. "Polynomial Goal Programming: A Procedure for Modeling Preference Trade-offs." Journal of Operational Management. Forthcoming.

Deckro, Richard F., Ronald W. Spahr, and John E. Hebert. 
"Preference Trade-Offs in Capital Budgeting Decisions Using Polynomial Goal Programming." IIE Transactions. 17:4. 332-337.

Dyer, James S. "Interactive Goal Programming." Management Science. 19 (1972). 62-70.

Harding, Ford, and Phillip D. Phillips. "Bull's Eye! How to Target the Right Industry for Your Community." Planning. 49. 18-20.

Harrold, J., J. Leotta, W. A. Wallace, and R. E. Wendell. "A Note on the Limitations of Goal Programming as Observed in Resource Allocation for Marine Environmental Protection." Naval Research Logistics Quarterly. 25:4 (1978). 733-739.

Ignizio, James P. Goal Programming and Extensions. Lexington, Mass.: Lexingtion Book Company, 1976. . "A Review of Goal Programming: A Tool for Multi-Objective Analysis." Journal of Operational Research Society. 29:11 (1978). 1109-1119. "An Augmented Linear Goal Programming Algorithm for Deriving the Efficient Solution Set." The Proceedings of the Fifteenth Annual Meeting of the Southeastern Chapter of TIMS. Richard F. Deckro and E. P. Winofsky, eds. (1979). 330-340.

Keeney, Ralph L, and Howard Raiffa. Decisions with Multiple Objectives: Preferences and Value Trade-Offs. New York: John Wiley \& Sons, 1976.

Khorramshahgol, R., and Y. Gousty. "Delphi Goal Programming (DGP): A Multi-Objective Cost/Benefit Approach to R\&D Portfolio Analysis." IEEE Transactions on Engineering Management. (August 1986.)

Kormbluth, J. S. H. "A Survey of Goal Programming." OMEGA. 1:2 (1973). 193-205.

Kort, John R. "Regional Economic Instability and Industrial Diversification in the U.S." Land Economics. 571
(November 1981). 596-608.

MacCrimmon, Kenneth R., and John K. Siu. "Making TradeOffs." Decision Sciences. 5 (1974). 680-704.

MacCrimmon, K., and M. Toda. "The Experimental Determination of Indifference Curves." The Review of Economic Studies. 36 (1969). 433-451.

Romero, Carlos. "A Survey of Generalized Goal Programming (1970-1982)." European Journal of Operational Research. 25:2. 183-191.

Rosenthal, Richard E. "Critique of Goal Programming." The Proceedings of the Fifteenth Annual Meeting of the Southeastern Chapter of TIMS. Richard F. Deckro and E. P. Winofsky, eds. (1979). 327-332.

Spahr, Ronald W., and Richard F. Deckro. "An Intraregional Economic Development Model Using Nonlinear Goal Programming." The Proceedings of the Thirteenth Annual Western AIDS. 154-156.

Thompson, Wilbur R. A Preface to Urban Economics. Baltimore, Md.: The John Hopkins Press for Resources for the Future, 1965.

Treyz, George I., Ann F. Freedlaender, and Benjamen H. Stevens. "The Employment Sector of a Regional Policy Simulation Model." The Review of Economics and Statistics. 62:1 (1980). 63-73.

Vining, Rutledge. "Regional Variation in Cyclical Fluctuations Viewed as a Frequency Distribution." Econometrica. 13 (1945). 183-213.

- "The Regional as a Concept in Business-Cycle Analysis." Econometrica. 14 (1946). 201-218.

Zanakis, Stelios H., and Sushil K. Gupta. "A Categorized Bibliographic Survey of Goal Programming." Omega. 13:3 (1985). 211-222.

Zeleny, Milan. Multiple Criteria Decision Making. New York: McGraw-Hill, 1982. 